\title{
Study on the Relationship between Students' Perceptions on Teachers and their English Learning in Multimedia-based Classroom Environment
}

\author{
Dan LIU \\ ${ }^{1}$ School of Foreign Languages, Wuhan Textile University, Wuhan, 430073, China \\ email: ellen_liu_2008@126.com
}

Keywords: English Learning; Multimedia-based Classroom; Perceptions on Teacher's Role

\begin{abstract}
This thesis adopts an empirical research with the initial purpose of investigating the relationship between students' perceptions on teacher's role and their English learning outcomes in multimedia-based college English classroom environment (MCECE). Meanwhile, the researcher also puts forward some proposals and suggestions for the future college English teaching. Moreover, it is vital to the cultivation teacher's computer skills, affective teaching, students' initiative learning skills and active participation in English study to facilitate students' English learning outcomes.
\end{abstract}

\section{Introduction}

Since environment has always been the necessity for language learners, especially for the Chinese English learners, classroom environment has always been regarded as the key element to learners' study. [1]Plenty of research abroad shows that: students' English learning achievements has much to do with their psychological perceptions on the classroom environment. [2] The study of classroom environment contains much theoretical and conceptual research like Murry (1938) and Lewin (1936) and later Getzels and Thelen (1960), Stern (1970) and Moos (1979), which has laid solid foundation for the later research work. [3]And with the study of classroom environment pervading, considerable research has been carried out to probe into the deep relationship between classroom environment and learners' cognitive and emotional outcomes (Fraser, 1986, 1998, 2002, 2007, 2009; Fraser \& Fisher, 1982; Haertel, Walberg \& Haertel, 1981; Walberg, 1976)and these studies have also pointed out the importance of a positive psychological classroom environment, and indicated that a positive perceptions on the classroom environment is of great necessity for the learners' learning achievements and learning attitudes. [4]

To fulfill the proposed purpose of the present study, the research questions are brought forward: (1) what's the general picture of students' perceptions on the multimedia-based college English classroom environment at the targeted university? (2) What is the correlation between students' perceptions on their teacher's role and students' learning outcomes in CET-4? Specifically: is there any difference between students with low and high proficiency in perceptions on their teacher's role in the multimedia-based English classroom environment?

\section{Methodology}

Research Subjects

The subjects in this present survey study include 90 non-English major college students (majoring in the Chinese and the Laws) of Grade 2010 at targeted University who have attended the CET-4 in December in 2011. 
Table 1 the Arrangement of Multimedia-Based College English Teaching Model

\begin{tabular}{ccc}
\hline Teaching model & $\begin{array}{c}\text { Teacher's face-to-face } \\
\text { coaching lessons }\end{array}$ & $\begin{array}{c}\text { Multimedia-based } \\
\text { autonomous learning lessons }\end{array}$ \\
\hline $\begin{array}{c}\text { Studying hours } \\
\text { (per week) }\end{array}$ & 2 studying hours & 2 studying hours \\
Teaching & Multimedia & Autonomous learning center \\
environment & classroom & (one computer each student) \\
\hline
\end{tabular}

Instruments

The quantitative instrument employed in this study refers to a questionnaire about the students' true perceptions on their multimedia-based college English classroom environment, which is designed with the reference of Sun Yunmei's (2009) questionnaire (College English Classroom Environment Inventory (CECEI) For Students' Version) adopted in the study of investigating the students' perceptions on the college English classroom environment in the traditional context. Based on this inventory, the researcher has made some modifications in order to be compatible with the current study, and also has amended some of the items in this inventory in accordance with the initial need to investigate the non-English major college students' perceptions on the multimedia-based English classroom environment.

Research Data collection of the questionnaire survey

The researcher selects a suitable chance when the two targeted classes have finished their study assignments before their final examinations of the third semester. The questionnaire survey inventory has been handed out during the subjects' English class, and they are asked to accomplish the questionnaire in 20 minutes under the guidance of the researcher, during which the participants are also required to look through each item carefully and think about how well each statement describes what their teacher's role is like in the multimedia-based English classroom environment, thus tick the number that best reflects their true feelings.

Quantitative Data Analysis

In the current study, the Statistical Packages for Social Sciences (SPSS) version 13.0 has been employed to analyze the collected quantitative data. Since the analysis of the collected quantitative data aims at solving the research questions put forward above, thus the research methods include: (1) the investigation of the descriptive statistics like frequency, percentage and mean values; (2) the difference analysis through the independent sample t-test as well as the correlation analysis and the multiple linear regression analysis are conducted to explore the relationship between students' perceptions on the teacher's role and their English learning outcomes in multimedia-based English classroom environment. As far as the qualitative data analysis goes, the researcher transcribes and selects the collected records with great caution to conclude the useful information according to the research objectives.

\section{Findings and Discussions}

Findings from the Quantitative Investigation

Research question No. one

Question 1: What's the general picture of students' perceptions on the multimedia-based college English classroom environment at targeted University?

In order to solve the first research question, it is necessary to carry out the analysis of descriptive statistics of the collected data by the SPSS13.0 Program. As the research has gathered the subjects' main personal information and their perceptions on the teacher's role in four dimensions in multimedia-based college English classroom environment, the data will be described and classified in statistics, which provides a general picture of students' extracurricular English learning time, distribution of their CET-4 scores, and the overall perceptions on teacher's role in multimedia-based English classroom environment. During this procedure, the Frequency 
distribution is described in forms of bar charts and tables, and besides, the Central Tendency which usually includes the Mode, Median and Mean as well as the Variance and the Standard Deviation are also shown in the following tables and figures. Bear in mind that the primary goal in investigating the descriptive statistics is to get a picture of what the targeted subjects' perceptions on the teacher's role in the multimedia context English classroom are like in general. First of all, the general picture of students' overall perceptions on the teacher's role in multimedia context English classroom is going to be displayed in table 2, table 3 and figure 1.

\begin{tabular}{|c|c|c|c|c|c|}
\hline & Group & Frequency & Percent & Valid Percent & $\begin{array}{c}\text { Cumulative } \\
\text { Percent } \\
\end{array}$ \\
\hline \multirow[t]{4}{*}{ Valid } & 1.00 & 14 & 17.1 & 17.1 & 17.1 \\
\hline & 2.00 & 23 & 28.0 & 28.0 & 45.1 \\
\hline & 3.00 & 45 & 54.9 & 54.9 & 100.0 \\
\hline & Total & 82 & 100.0 & 100.0 & \\
\hline
\end{tabular}

Figure1 Bar Chart of the Students’ Overall Perception

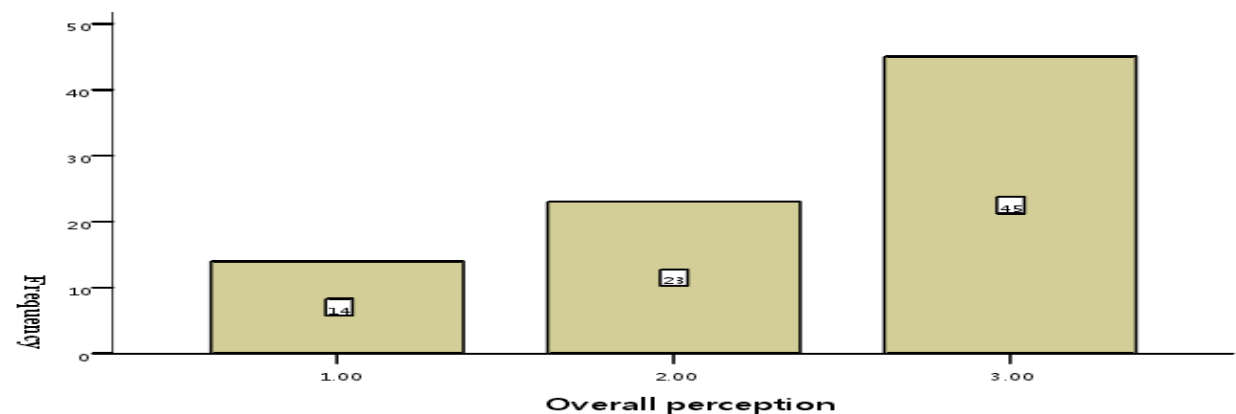

According to table 2 and figure 1, it is concluded that frequency of group3 (standing for scores from 131 to 140 ) reaches 45 which takes 54.9 percent of the whole population's perceptions, and group 2 (standing for scores from 121 130) has also reaches the 28.0 percent according to its frequency $(\mathrm{F}=23)$, and group 1 only has a percentage of 17.1 , which is the lowest frequency $(\mathrm{F}=14)$.

Table 3 Statistics of Students' Overall Perceptions

\begin{tabular}{lrr}
\hline $\mathrm{N}$ & Valid & 82 \\
& Missing & 0 \\
\hline Mean & & 128.5976 \\
Median & 131.0000 \\
Mode & 140.00 \\
Std. Deviation & 10.33018 \\
Variance & 106.713 \\
Range & 40.00 \\
\hline
\end{tabular}

Meanwhile, as table 3 shows, we can easily find that the mean of the perception score reaches as high as approximately 129 (128.5976), and the mode of the perception score is 140, both of which indicates that most students have a high degree of the perceptions on the multimedia-based classroom in terms of teacher's role. In addition, the variance is 106.713, which is much lower than the coefficient of mean (mean $=128.5976$ ), and the standard deviation here only reaches 10.33108. Both of which imply that there is no significant difference in the general perceptions of the teacher's role in the multimedia-based English classroom environment, and the majority are in a positive perception on their teacher's role. Therefore, it is concluded from the data obtained and presented above that most students have more positive perceptions on the multimedia-based English classroom environment as a whole.

Research question No. two

Question 2: What is the correlation between students' perceptions on their teacher's role and students' learning outcomes in CET-4? Specifically: is there any difference between students with 
low-and high-proficiency in perceptions on their teacher's role in the multimedia-based English classroom environment?

When it comes to this question, it is definitely necessary to turn to the analysis results of the Mean, Standard Deviation and the Independent Sample t-Test for differences in the comparison between students' perceptions of MCECE and their different levels in CTE-4. Therefore, in order to conduct the study of the difference between comparison of students' MCECE perceptions and students' English achievements, the researcher takes the research subjects' scores of CET-4 as the reference standard, which have been obtained in the first part (personal information) of the questionnaire survey during the procedure of quantitative data collection. After one year's attendance of the multimedia-based college English teaching mode, the participants then took part in this CET-4 in December, 2011, whose scores have been collected and sorted into the upper group (scores above 540) and the lower group (scores below 470) for the purpose of analyzing and studying the differences comparison between the MCECE perceptions and students' English achievements in terms of the different levels of CET-4 score. Therefore, the methodology employed in this section is the Independent Sample t Test to evaluate whether there is difference between students with different scores of CET-4 and their perceptions on the MCECE.

After analyzing the collected data by using the SPSS program, the outcome of the students' (upper group and the lower group) perceptions on the MCECE in terms of the Mean, Standard Deviation and t Test for Independent Sample for differences is displayed in table 4.

Table 4 Mean Standard Deviation and Independent Sample t Test for the Differences Between Students’ Perceptions on MCECE and Their Different Levels in CET-4 Scores

\begin{tabular}{|c|c|c|c|c|c|c|c|}
\hline \multirow[t]{2}{*}{ Factors } & \multirow{2}{*}{$\begin{array}{l}\text { No. } \\
\text { of } \\
\text { Item }\end{array}$} & \multicolumn{2}{|c|}{ Mean } & \multicolumn{2}{|c|}{ Standard Deviation } & \multirow[t]{2}{*}{$\mathrm{t}$} & \multirow{2}{*}{$\begin{array}{l}\text { Sig. } \\
\text { 2-tail } \\
\text { ed) }\end{array}$} \\
\hline & & Upper & Lower & Upper & Lower & & \\
\hline Teacher support & 7 & 37.4118 & 36.0000 & 2.20960 & 3.70810 & $1.349 *$ & 0.001 \\
\hline Leadership & 8 & 31.9412 & 28.5294 & 2.41015 & 2.98156 & $3.669 * *$ & 0.000 \\
\hline Equity & 5 & 23.9412 & 22.8235 & 1.43486 & 2.37790 & 1.659 & 0.107 \\
\hline Innovation & 8 & 37.0000 & 35.1765 & 2.80624 & 5.02786 & $1.306^{*}$ & 0.001 \\
\hline
\end{tabular}

$\left({ }^{*} \mathrm{p}<0.05 * * \mathrm{p}<0.001\right.$ ( $\mathrm{N}=21$ students with higher scores and 21students with lower scores in CET-4)

According to table 4, it is evident to see that the D-value of Standard Deviation in the Upper group is higher than that in Lower group, which indicates that students in the Upper group perceive much more positively than those in the Lower one in all the factors, and their perceptions on all the four factors in MCECE are more satisfactory. Meanwhile, from the perspective of the $t$ test, the significant differences between different levels in the factors like teacher support (reaching 0.001), leadership (reaching 0.000), and innovation (reaching 0.001) are easily found, one of which even reaches 0.000 (factor of Leadership), which shows that students are aware of the teacher's role in MCECE, and they can make full use of teacher's role to assist their English learning, especially for the students in upper group concerning the results of the Mean and Standard Deviation. However, there is no any obvious difference on the scale of equity. 
Table 5 Correlations between Total Scores of Students’ Perceptions and Their CET-4 Scores

\begin{tabular}{llrr}
\hline & & Perceptions & \multicolumn{1}{c}{ CET4 } \\
\hline Perceptions & Pearson Correlation & 1.000 & $\mathbf{0 . 3 2 8 ( ^ { * * } )}$ \\
& Sig. (1-tailed) & & $\mathbf{0 0 1}$ \\
& $\mathrm{N}$ & 82 & $\mathbf{8 2}$ \\
\hline CET4 & Pearson Correlation & $\mathbf{0 . 3 2 8}\left(^{* *}\right)$ & 1.000 \\
& Sig. (1-tailed) & $\mathbf{0 0 1}$ & \\
& $\mathrm{N}$ & $\mathbf{8 2}$ & 82 \\
\hline
\end{tabular}

** Correlation is significant at the 0.01 level (2-tailed).

Table 5 shows the correlations between total scores of students' perceptions on the MCECE and their CET-4 scores, and the correlation coefficient has reached 0.328 , which indicates that there is a positive linear relationship between the two variables, and the significant correlation reaches 0.01 levels. Therefore, students' English learning outcomes has much to do with the perceptions on the MCECE, thus the establishment of a favorable MCECE should be addressed by both the students and the teacher.

Summary of the Findings and Discussions

The descriptive analysis and statistical findings indicate that: firstly, most of the students generally hold a positive perception on the multimedia-based English classroom environment. Besides, participants in this study, who have much difference in perception on the same teacher's role, are in different levels in CET-4 scores, and there exists a positive and significant relationship between students' perception levels and their CET-4 scores, i.e. the more positively the participants in this study perceive, the higher their scores will be. Therefore, it is of utmost importance for schools to further strengthen the application of the computer technology into college English teaching; great priority should be given to the teacher's role in multimedia-based English classroom environment so as to establish a positive and harmonious English classroom environment, and to facilitate teaching efficiency and accelerate students' English learning outcomes; students themselves should be initiative and positive in English study.

\section{Conclusion}

The study has proved that there is a positive relationship between students' perceptions on teacher's role in MCECE and their English learning outcomes, and has revealed some major findings pertaining to English classroom environment and students' academic outcomes, which provides useful pedagogical implications in many aspects. [5]Limitations of This Study: the limited research subjects. This study is only carried out in one university and two majors of the Art, which has involved on a small scale of samples. Recommendations for the Future Research: As the focus of this study is to probe into the impact of students' perceptions of the teacher's role on students' English learning outcomes in MCECE, the researcher takes the CET-4 as a reference of students' learning achievements. And therefore, it is suggested that the future similar empirical study of students' English learning outcomes should make use of some other references regarding to students' English academic development.

\section{References}

[1] Chapelle, C. (2007). Challenges in evaluation of innovation: Observations from technology research. Innovation in Language Learning and Teaching, 1(1), 30-45.

[2] Dorman, J. P. (2001). Associations between Classroom Environment and Academic Efficacy [J], Learning Environments Research, 4, 243-257.

[3] Aldridge, J.M., \& Fraser, B.J. (2000). A cross-cultural study of classroom learning environments in Australia and Taiwan [J]. Learning Environments Research, 3, 101-134.

[4] Ellis, R. (1997). Second language acquisition. Oxford: Oxford University Press. 
[5] Goth, S.C., Young, D.J., \& Fraser, B.J. (1995). Psychosocial Climate and Student Outcomes in Elementary Mathematics Classrooms: A Multilevel Analysis [J], Journal of Experimental Education, 64, 29-40. 